\title{
Quartz-Enhanced Photoacoustic Spectroscopy Sensor with a Small-Gap Quartz Tuning Fork
}

\author{
Yu-Fei Ma * (D), Yao Tong, Ying He, Jin-Hu Long and Xin Yu \\ National Key Laboratory of Science and Technology on Tunable Laser, Harbin Institute of Technology, \\ Harbin 150001, China; tongyao9505@163.com (Y.T.); hearkenyi@hit.edu.cn (Y.H.); ljh65923@163.com (J.-H.L.); \\ yuxin0306@hit.edu.cn (X.Y.) \\ * Correspondence: mayufei@hit.edu.cn; Tel.: +86-451-86413161
}

Received: 10 May 2018; Accepted: 25 June 2018; Published: 27 June 2018

\begin{abstract}
A highly sensitive quartz-enhanced photoacoustic spectroscopy (QEPAS) sensor based on a custom quartz tuning fork (QTF) with a small-gap of $200 \mu \mathrm{m}$ was demonstrated. With the help of the finite element modeling (FEM) simulation software COMSOL, the change tendency of the QEPAS signal under the influence of the laser beam vertical position and the length of the micro-resonator $(\mathrm{mR})$ were calculated theoretically. Water vapor $\left(\mathrm{H}_{2} \mathrm{O}\right)$ was selected as the target analyte. The experimental results agreed well with those of the simulation, which verified the correctness of the theoretical model. An 11-fold signal enhancement was achieved with the addition of an $\mathrm{mR}$ with an optimal length of $5 \mathrm{~mm}$ in comparison to the bare QTF. Finally, the $\mathrm{H}_{2} \mathrm{O}$-QEPAS sensor, which was based on a small-gap QTF, achieved a minimum detection limit (MDL) of $1.3 \mathrm{ppm}$, indicating an improvement of the sensor performance when compared to the standard QTF that has a gap of $300 \mu \mathrm{m}$.
\end{abstract}

Keywords: QEPAS; small-gap QTF; gas sensor; COMSOL

\section{Introduction}

Quartz-enhanced photoacoustic spectroscopy (QEPAS) is a sensitive gas sensing technique that was invented in 2002 [1]. As an innovation based on traditional photoacoustic spectroscopy (PAS), QEPAS utilizes a millimeter-sized quartz tuning fork (QTF) as an acoustic transducer instead of a wide-band microphone employed in PAS. With merits including high sensitivity, compactness, fast response, and a large dynamic range, QEPAS has found applications in the detection of numerous trace gases [2-8].

The performance of a QEPAS sensor system is correlated with the measured signal value. Therefore, it is necessary to maximize the signal. An improvement of the QEPAS signal can be achieved by an increase in optical excitation power. In Ma et al. [9], a quantum cascade laser (QCL) was used as the excitation because the output power can reach $1000 \mathrm{~mW}$. An erbium-doped fiber amplifier (EDFA) with an output power of $\sim 1200 \mathrm{~mW}$ was utilized to amplify the output laser in Wu et al. and Ma et al. [10,11]. In Lassen et al. [12], an off-beam QEPAS sensor using a pulsed nanosecond mid-infrared optical parametric oscillator with an average output power of approximately $400 \mathrm{~mW}$ was demonstrated. Additionally, an optimization of the dimensions of the QTF and the structure of the acoustic detection module could also improve QEPAS sensor performance [13-17].

QTF, a crystal component, is produced by photolithographic and chemical etching techniques [18]. Historically, QTF was used to provide the clock rate in crystal watches, timers, and electronic circuits. The unique acoustic quadrupole structure of a QTF provides an excellent immunity to environment interference [19]. With a U-shape geometry, a QTF consists of two quartz fork tines and a hollow fork valley. The acoustic wave causes resonance vibration, thereby accumulating the energy in the 
QTF. Standard commercial QTFs possess a resonance frequency, $f_{0}$, of $32.768 \mathrm{kHz}$ and a Q-factor of $\sim 10,000$ in standard atmosphere pressure. The width of the fork valley, the so-called gap, determines the space for acoustic wave generation. Traditional QTFs with a gap of $300 \mu \mathrm{m}$ cannot satisfy the requirement when the excitation beam size exceeds the gap dimension. Therefore, adjusting the size of the QTF is a method to improve sensor performance [20,21]. In Borr et al. [21], a custom-made QTF with a $1 \mathrm{~mm}$-wide prong spacing was used in terahertz $(\mathrm{THz})$ spectral region detection. As the big beam waist diameter of the $\mathrm{THz}$ laser is larger than $\sim 400-500 \mu \mathrm{m}$, this results in blockage of laser beam radiation by the times of a commercial QTF [18]. Nevertheless, in the near-infrared range, the diameter of the laser beam is far smaller than that in the $\mathrm{THz}$ spectral region.

The laser beam passes through the fork valley and excites the gas molecules. Notably, the sound wave generated by the reaction between the laser beam and the gas molecules can be viewed as spherical wave oscillation. Figure 1 shows the schematic diagram of the laser beam, a QTF, and the associated sound wave. The spherical wave propagation decreases with the cube of the distance, which suggests that the energy of the sound wave will diminish rapidly as the distance from the generation source point of the sound wave increases. From this perspective, employing a small-gap QTF can avoid energy losses and therefore improve the signal level of the QEPAS sensor.

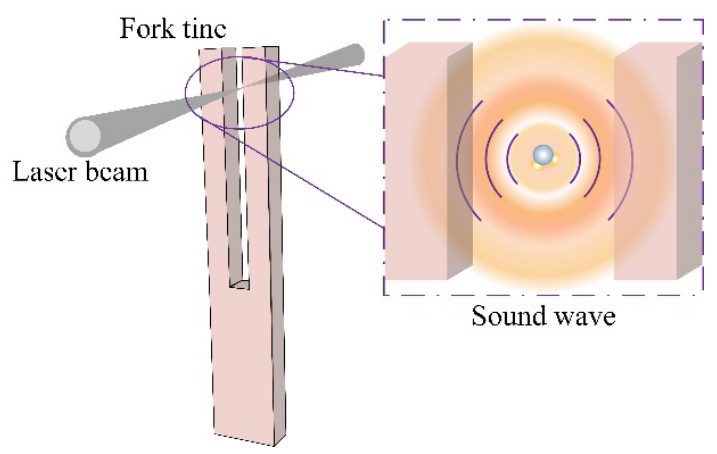

Figure 1. The schematic diagram of a quartz tuning fork (QTF), the laser excitation beam, and the generated sound wave.

In this paper, the improvement of a QEPAS sensor detection sensitivity using a QTF with a small-gap of $200 \mu \mathrm{m}$ was demonstrated for the first time. Firstly, on the basis of the finite element modeling (FEM) of COMSOL software, a simulation of the optimal vertical position with respect to the QTF and the length of a micro-resonator was presented. Subsequently, water vapor $\left(\mathrm{H}_{2} \mathrm{O}\right)$ with an absorption line located at $7168.4 \mathrm{~cm}^{-1}$ was chosen as the target. Experimental results agreed well with the theoretical simulations and an improvement of QEPAS performance using the small-gap QTF was achieved.

\section{Experimental Setup}

The basic design of the experimental setup is shown in Figure 2. A distributed feedback (DFB) diode laser with an output wavelength of $1.39 \mu \mathrm{m}$ was employed. The jitter of the diode laser output power was less than $1 \%$. The laser beam quality was measured and the beam quality factor $\mathrm{M}^{2}$ was found to be 1.03 at an output power of $10.5 \mathrm{~mW}$ when the $\mathrm{H}_{2} \mathrm{O}$ absorption line was targeted. The scanning of wavelengths was completed by adding a voltage ramp as a current driver. Additionally, a sinusoidal signal with a frequency of $f_{0} / 2$ was applied to modulate the laser. After collimation, the diode laser beam was focused into the QTF valley. The laser beam size at the focal point was $\sim 42 \mu \mathrm{m}$ when a lens with a focal length of $60 \mathrm{~mm}$ was used. Because the generated piezoelectric current signal was too weak to detect directly, a custom-made transimpedance amplifier (TA) with a feedback resistance of $10 \mathrm{M} \Omega$ was used to amplify the QTF signal. The voltage signal was delivered to a lock-in amplifier, where it was demodulated into a second harmonic signal ( $2 f)$. The integration time for the 
QEPAS sensor was $1 \mathrm{~s}$. A serial port (RS232) provided an output for the data flow from the lock-in amplifier to a personal computer (PC). A custom-made, small-gap QTF was employed in this research. The dimensions of the QTF are shown in Table 1.

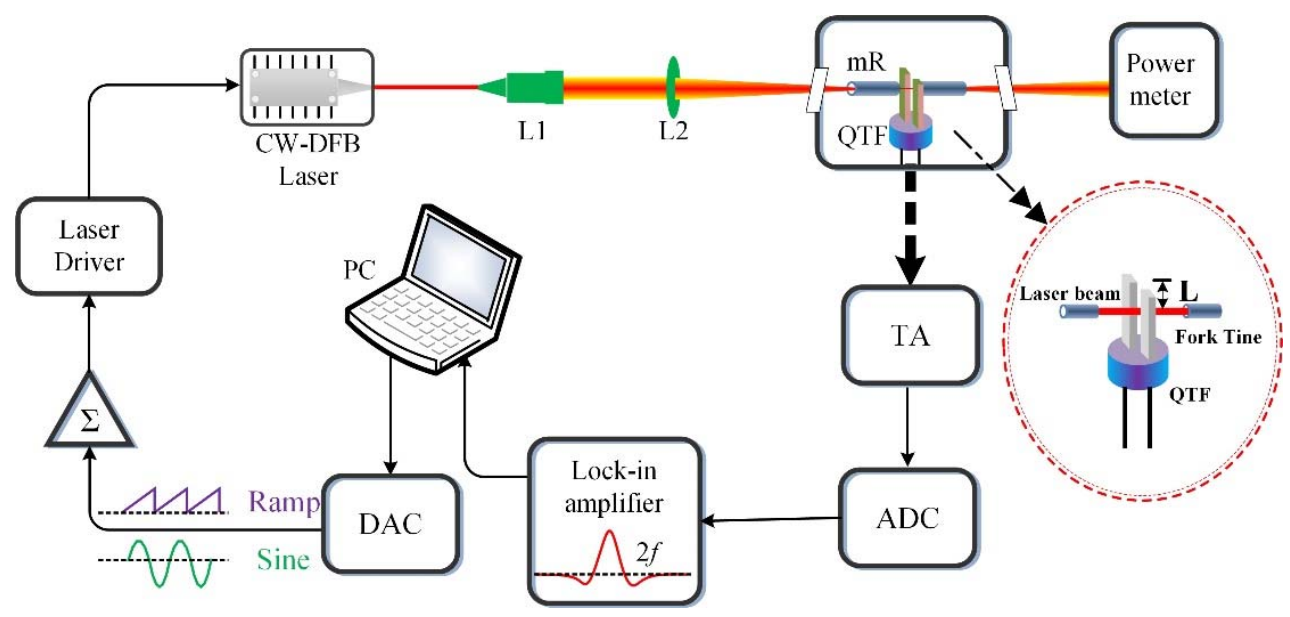

Figure 2. Schematic of the quartz-enhanced photoacoustic spectroscopy (QEPAS) sensor system.

Table 1. Dimensions and parameters of the small-gap QTF.

\begin{tabular}{cccc}
\hline & Parameter & Unit & Small-Gap QTF \\
\hline \multirow{4}{*}{ QTF } & Measured frequency $f_{0}$ & $\mathrm{~Hz}$ & $32,754.27$ \\
& Gap & $\mu \mathrm{m}$ & 200 \\
& Q factor & - & 8179 \\
\multirow{3}{*}{ Fork tine } & Length & $\mathrm{mm}$ & 3.42 \\
& Thickness & $\mathrm{mm}$ & 0.44 \\
& Width & $\mathrm{mm}$ & 0.3 \\
\hline
\end{tabular}

\section{Theoretical Simulations}

In this section, an acoustic generation module formed by the QTF and a cone laser beam was simulated using the FEM COMSOL software. Invoking the acoustic module and structural mechanics module, a finite element model was constructed to calculate the vibration modes in varying conditions [22]. An illustration in Figure 2 depicts the definition of L, which represents the distance between the unfixed top of the fork tine and the laser beam. The deformation of the QTF with the laser beam radiating at $\mathrm{L}=0 \mathrm{~mm}, \mathrm{~L}=0.5 \mathrm{~mm}$, and $\mathrm{L}=2 \mathrm{~mm}$ is shown in Figure 3 . The black solid lines represent the inherent shape of the QTF while the multicolor region represents the deformation caused by the acoustic wave. A color bar is used to represent the deformation value. It can be seen that a maximal pendulum deflection occurred at the condition of $\mathrm{L}=0.5 \mathrm{~mm}$. For comparison, a standard QTF with a gap of $300 \mu \mathrm{m}$ is also presented in Figure 3.

The simulated QEPAS normalized displacement with various values of $L$ for two different QTFs is shown in Figure 4 . The calculated range was $0-2 \mathrm{~mm}$ with a $0.1 \mathrm{~mm}$ step size. As the diode laser beam moved down relative to the QTF, the normalized signal amplitude increased rapidly in the range of $0-0.5 \mathrm{~mm}$ and kept decreasing within the range of $0.5-2 \mathrm{~mm}$ for the QTF with a $200 \mu \mathrm{m}$ gap. The optimum vertical position was $\mathrm{L}=0.5 \mathrm{~mm}$ based on the simulated results. For the standard QTF with a $300 \mu \mathrm{m}$ gap, the optimum vertical position $\mathrm{L}$ was $0.7 \mathrm{~mm}$. The calculated maximum displacement for the small-gap QTF with $200 \mu \mathrm{m}$ gap and the standard QTF with $300 \mu \mathrm{m}$ gap were $1.96 \times 10^{-10} \mathrm{~mm}$ and $1.82 \times 10^{-10} \mathrm{~mm}$, respectively. 
(mm)

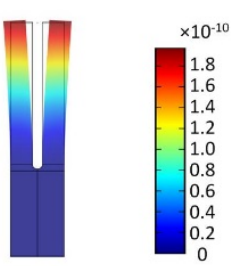

(a) $\mathrm{L}=0 \mathrm{~mm}$ (mm)

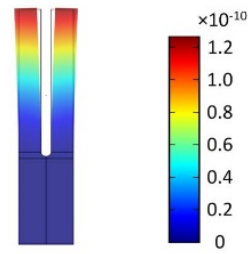

(c) $\mathrm{L}=2 \mathrm{~mm}$ (mm)

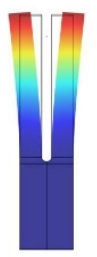

QTF with a $200 \mu \mathrm{m}$ gap

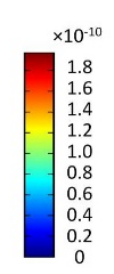

(b) $\mathrm{L}=0.5 \mathrm{~mm}$

$(\mathrm{mm})$

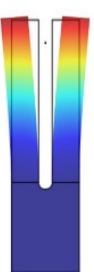

(e) $\mathrm{L}=0.5 \mathrm{~mm}$ (mm)

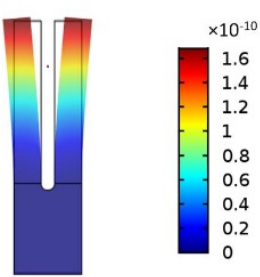

(f) $\mathrm{L}=2 \mathrm{~mm}$

(d) $\mathrm{L}=0 \mathrm{~mm}$

Standard QTF with a $300 \mu \mathrm{m}$ gap

Figure 3. Calculated deformation with various acoustic wave excitation positions (L) for two different QTFs: (a-c) for the QTF with a $200 \mu \mathrm{m}$ gap; (d-f) for the standard QTF with a $300 \mu \mathrm{m}$ gap.

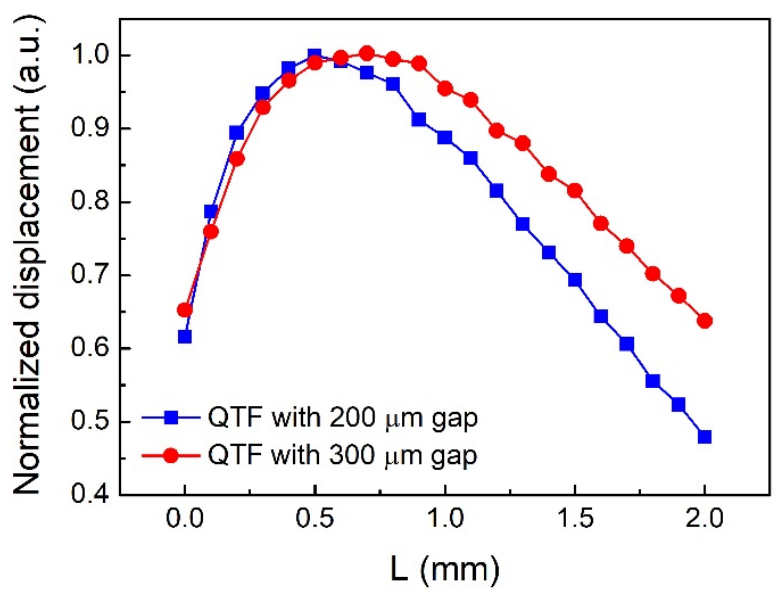

Figure 4. Normalized calculated displacement as a function of vertical height (L) for two different QTFs.

It was demonstrated that two metal micro-resonators (mRs) could improve the QEPAS signal as a result of the acoustic coupling between the two mRs and the QTF architecture. In Dong et al. [23], the optimal length of $\mathrm{mR}$ was shown to be $\lambda \mathrm{s} / 4 \sim \lambda \mathrm{s} / 2$ where $\lambda \mathrm{s}$ was the sound wavelength. Therefore, the optimal length range of $\mathrm{mR}$ was calculated to be $2.6-5.2 \mathrm{~mm}$ with the sound velocity of $340 \mathrm{~m} / \mathrm{s}$ and the resonance frequency of $32.768 \mathrm{kHz}$. In the following simulations, the dimensions of $\mathrm{mR}$ tubes were set with an inner diameter of $0.5 \mathrm{~mm}$ and an outer diameter of $1.27 \mathrm{~mm}$, which was in agreement with the $\mathrm{mRs}$ in the laboratory. On the basis of the investigation by Dong et al. [23], in this research, the gap between the QTF surface and the end of the mRs was set to be $25 \mu \mathrm{m}$ for a strong acoustic coupling. The displacement of the fork tines was calculated for mRs with the length of $3 \mathrm{~mm}, 4 \mathrm{~mm}, 5 \mathrm{~mm}$, and $6 \mathrm{~mm}$. The sound wave generated position was set at $\mathrm{L}=0.5 \mathrm{~mm}$ for the QTF with a small gap 
of $200 \mu \mathrm{m}$. The simulated diagrams of $3 \mathrm{~mm}, 5 \mathrm{~mm}$, and $6 \mathrm{~mm}$ are shown in Figure 5. A transparent column and a blue-filled column, which symbolized the mRs, were placed at the two sides of the QTF. It can be seen that a larger displacement was achieved with an $\mathrm{mR}$ of $5 \mathrm{~mm}$. For the standard QTF with a $300 \mu \mathrm{m}$ gap, the $\mathrm{L}$ was set to be $0.7 \mathrm{~mm}$ in the simulation. The calculated results are also presented in Figure 5 and the maximum displacement was obtained when the length of $\mathrm{mR}$ was $5 \mathrm{~mm}$. The calculated normalized displacement with different $\mathrm{mRs}$ is shown in Figure 6. The enhancement effect of the $\mathrm{mR}$ from high to low was in the order of $5 \mathrm{~mm}, 4 \mathrm{~mm}, 6 \mathrm{~mm}, 3 \mathrm{~mm}$.

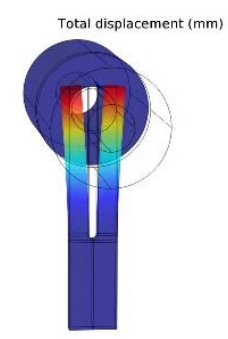

(a) $\mathrm{mR}=3 \mathrm{~mm}$

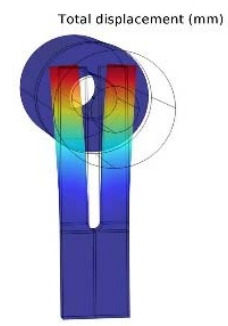

(d) $\mathrm{mR}=3 \mathrm{~mm}$
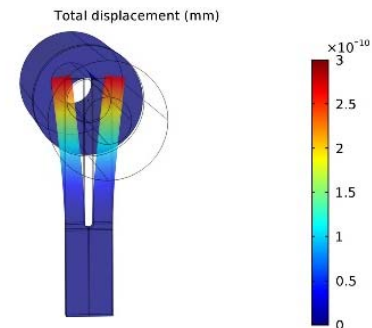

(b) $\mathrm{mR}=5 \mathrm{~mm}$ QTF with a $200 \mu \mathrm{m}$ gap

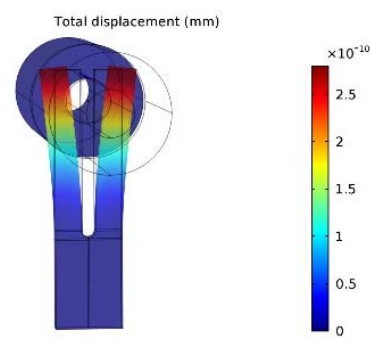

(e) $\mathrm{mR}=5 \mathrm{~mm}$

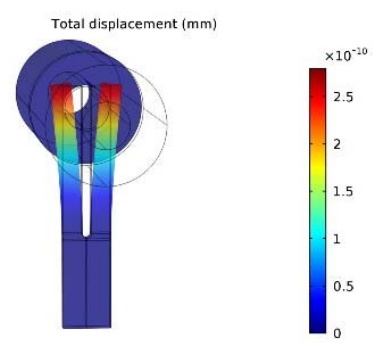

(c) $\mathrm{mR}=6 \mathrm{~mm}$

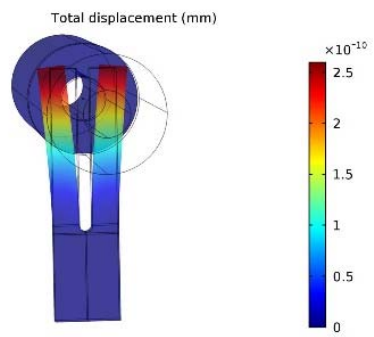

(f) $\mathrm{mR}=6 \mathrm{~mm}$

Standard QTF with a $300 \mu \mathrm{m}$ gap

Figure 5. Calculated displacement with various micro-resonators (mRs) for two different QTFs: (a-c) for the QTF with a $200 \mu \mathrm{m}$ gap; (d-f) for the standard QTF with a $300 \mu \mathrm{m}$ gap.

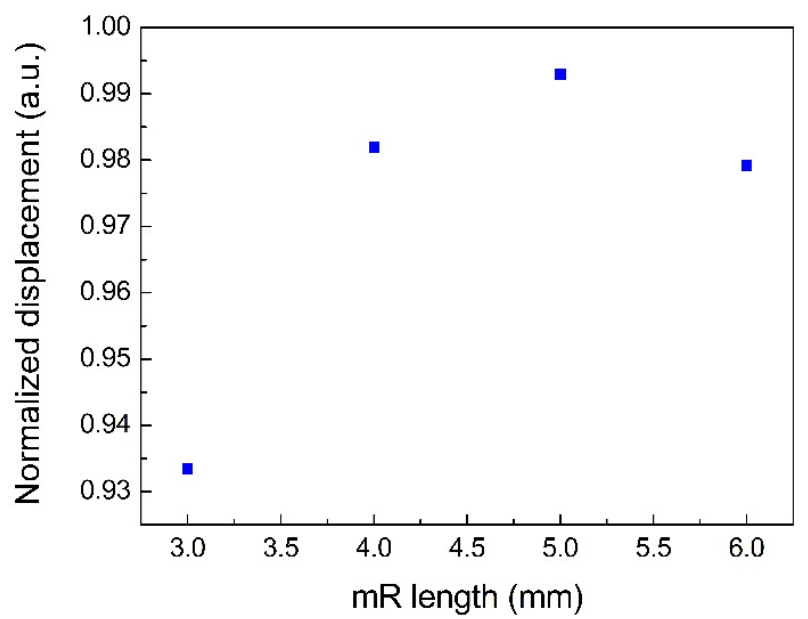

Figure 6. Calculated normalized displacement as a function of $\mathrm{mR}$ length.

\section{Results and Discussion}

As mentioned above, water vapor $\left(\mathrm{H}_{2} \mathrm{O}\right)$ was selected as the target analyte and a QTF with a small-gap of $200 \mu \mathrm{m}$ was adopted. The acoustic wave excitation position generated by the diode laser 
beam was optimized experimentally and the result is shown in Figure 7. The experiment was carried out with a laser wavelength modulation depth of $0.39 \mathrm{~cm}^{-1}$. The experimental results were often identical to the FEM simulations and the optimal position of $L$ for the maximal signal amplitude was found to be $0.5 \mathrm{~mm}$. Therefore, in the following experiments $\mathrm{L}=0.5 \mathrm{~mm}$ was chosen.

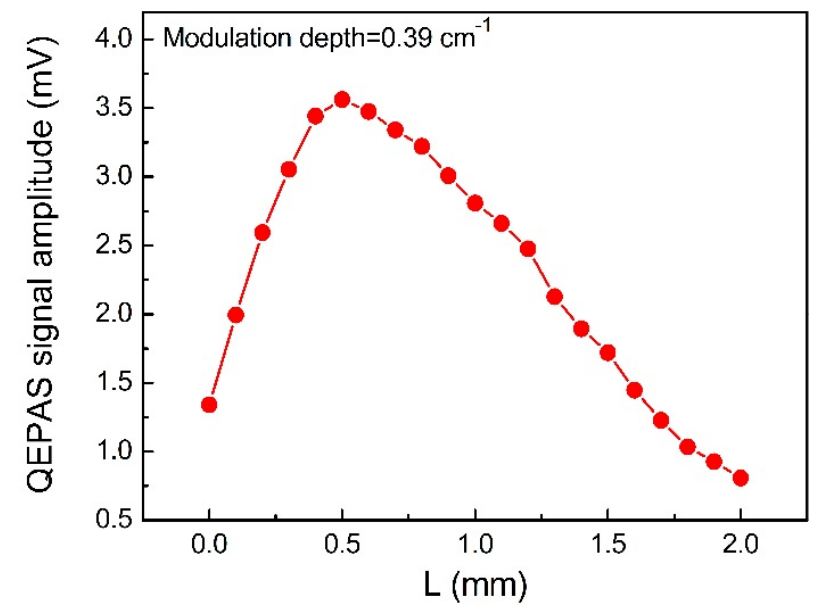

Figure 7. Experimental measured $\mathrm{H}_{2} \mathrm{O}-\mathrm{QEPAS}$ signal amplitude as a function of the vertical height of the laser beam.

An optimization of the modulation depth was implemented to improve the $2 f$ signal level. The laser modulation was completed by adding a voltage ramp with low frequency and a sinusoidal signal with a frequency of $f_{0} / 2$. The experimental results are shown in Figure 8 . When the modulation depth was small, the modulation amplitude fell short of covering the $\mathrm{H}_{2} \mathrm{O}$ absorption line. Therefore, the QEPAS signal amplitude was weak. The $\mathrm{H}_{2} \mathrm{O}$-QEPAS signal level increased with an increase of the modulation depth. The curve declined when the modulation depth was greater than $0.49 \mathrm{~cm}^{-1}$. Ultimately, the optimum modulation depth was determined to be $0.49 \mathrm{~cm}^{-1}$.

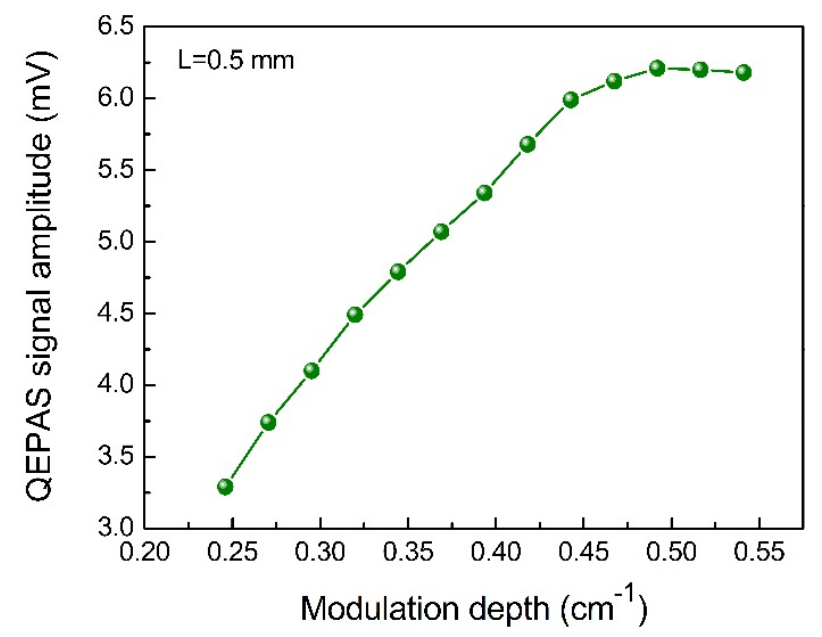

Figure 8. Experimental measured $\mathrm{H}_{2} \mathrm{O}-\mathrm{QEPAS}$ signal amplitude as a function of modulation depth.

The range of 2.8 5.5 $\mathrm{mm}$ was the optimum length of the $\mathrm{mR}$ tubes, as mentioned before. The $2 f$ signal measured following the addition of mRs of different lengths at the optimum modulation depth of $0.49 \mathrm{~cm}^{-1}$ is shown in Figure 9. The maximum signal level was achieved when the $\mathrm{mR}$ tubes with a length of $5.0 \mathrm{~mm}$ were used, followed by the lengths of $4 \mathrm{~mm}, 6 \mathrm{~mm}$, and $3 \mathrm{~mm}$. These results were consistent with those of the simulation. The maximal signal of $65.6 \mathrm{mV}$ achieved an 
11-fold amplification when compared to the signal generated by the bare small-gap QTF. The noise value was $29.6 \mu \mathrm{V}$, which was obtained by taking the standard deviation of signal points distant from the absorption peak. The integration time for the noise determination was the same as the signal measurement. With a water vapor concentration of $0.296 \%$ (with air temperature at $\sim 13^{\circ} \mathrm{C}$ ), the minimum detection limit (MDL), which represents the detection performance of sensor, was calculated to be 1.3 parts per million (ppm). The calculated normalized noise equivalent absorption coefficient (NNEA) was $1.42 \times 10^{-8} \mathrm{~cm}^{-1} \mathrm{~W} / \sqrt{ } \mathrm{Hz}$.

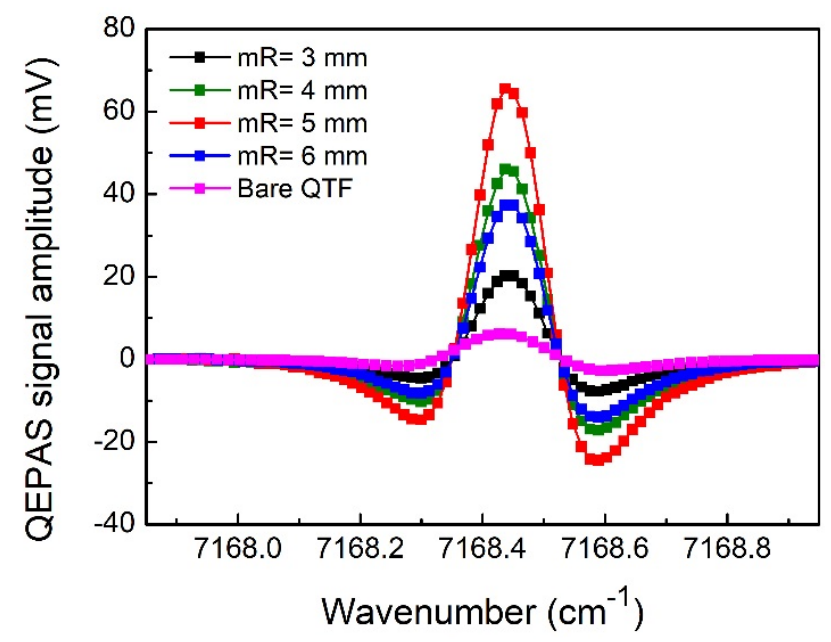

Figure 9. Experimental measured $2 f$ QEPAS signals using mRs with different lengths

When an $\mathrm{mR}$ with a length of $4 \mathrm{~mm}$ was used, a signal enhancement of 7.5 times was obtained, resulting in an MDL of $1.85 \mathrm{ppm}$ and a NNEA of $2.02 \times 10^{-8} \mathrm{~cm}^{-1} \mathrm{~W} / \sqrt{ } \mathrm{Hz}$ for this $\mathrm{H}_{2} \mathrm{O}$-QEPAS sensor using a QTF with a small-gap of $200 \mu \mathrm{m}$. For comparison, the MDL and NNEA for the $\mathrm{H}_{2} \mathrm{O}-\mathrm{QEPAS}$ sensor using a standard QTF with a gap of $300 \mu \mathrm{m}$ and an $\mathrm{mR}$ of $4 \mathrm{~mm}$ and a laser power of $12.6 \mathrm{~mW}$ were $5.9 \mathrm{ppm}$ and $7.73 \times 10^{-8} \mathrm{~cm}^{-1} \mathrm{~W} / \sqrt{ } \mathrm{Hz}$, respectively [24]. This significant improvement can be explained as follows. On one hand, the small-gap QTF, with a lower energy loss of diffusion, allowed the acoustic wave energy to push the fork tines more efficiently. On the other hand, a decrease of the fork tine mass compared to that of a commercial QTF may lead to a larger displacement.

\section{Conclusion}

In conclusion, a sensitive QEPAS sensor employing a custom small-gap QTF as an acoustic wave transducer was demonstrated in this paper for the first time. Firstly, on the basis of the finite element modeling (FEM) software COMSOL, a theoretical model was built to predict the tendency of the QEPAS signal when both the position of the diode laser beam and the length of the $\mathrm{mR}$ were changed. Water vapor was chosen as the target analyte. Experiments were carried out and the experimental results matched well with those of the simulation. The maximum $2 f$ signal level was obtained when the laser beam was $0.5 \mathrm{~mm}$ away from the end of the tine and the $\mathrm{mR}$ length was $5 \mathrm{~mm}$. The optimized laser wavelength modulation depth was found to be $0.49 \mathrm{~cm}^{-1}$. Furthermore, a $5 \mathrm{~mm} \mathrm{mR}$ yielded a detection sensitivity enhancement factor of 11 with respect to the bare QTF. Finally, an MDL of $1.3 \mathrm{ppm}$ was achieved at a $1 \mathrm{~s}$ integration time. It can be seen that a small-gap QTF increases the acoustic wave energy strength between the fork tines and, therefore, enhances the QEPAS sensor performance. The detection limit can be further improved when a QTF with an optimum gap is adopted.

Author Contributions: Y.-F.M. was the group leader. Y.T. partly performed experiments and prepared this manuscript. Y.H. was in charge of theoretical simulation. J.-H.L. participated in the simulation and was involved in discussions. X.Y. provided valuable guidance of the experiments. All authors were involved in numerous discussions related in all aspects of this paper. 
Funding: This work was supported by the National Natural Science Foundation of China (Grant No. 61505041), the Natural Science Foundation of Heilongjiang Province of China (Grant No. F2015011), the Application Technology Research and Development Projects of Harbin (No. 2016RAQXJ140), and the Fundamental Research Funds for the Central Universities.

Acknowledgments: We are particularly grateful to Frank K. Tittel for his help in revising this manuscript.

Conflicts of Interest: The authors declare no conflict of interest.

\section{References}

1. Kosterev, A.A.; Bakhirkin, Y.A.; Curl, R.F.; Tittel, F.K. Quartz-enhanced photoacoustic spectroscopy. Opt. Lett. 2002, 27, 1902-1904. [CrossRef] [PubMed]

2. He, Y.; Ma, Y.F.; Tong, Y.; Yu, X.; Peng, Z.F.; Gao, J.; Tittel, F.K. Long distance, distributed gas sensing based on micro-nano fiber evanescent wave quartz-enhanced photoacoustic spectroscopy. Appl. Phys. Lett. 2017, 111, 241102. [CrossRef]

3. Wang, Z.; Li, Z.; Ren, W. Quartz-enhanced photoacoustic detection of ethylene using a $10.5 \mu \mathrm{m}$ quantum cascade laser. Opt. Express 2016, 24, 4143-4154. [CrossRef] [PubMed]

4. Yi, H.M.; Maamary, R.; Gao, X.M.; Sigrist, M.W.; Fertein, E.; Chen, W.D. Short-lived species detection of nitrous acid by external-cavity quantum cascade laser based quartz-enhanced photoacoustic absorption spectroscopy. Appl. Phys. Lett. 2015, 106, 101109. [CrossRef]

5. Nguyen, B.T.; Triki, M.; Desbrosses, G.; Vicet, A. Quartz-enhanced photoacoustic spectroscopy sensor for ethylene detection with a $3.32 \mu \mathrm{m}$ distributed feedback laser diode. Rev. Sci. Instrum. 2015, 86, 023111. [CrossRef] [PubMed]

6. Lendl, B.; Moser, H.; Waclawek, J.P. Compact quantum cascade laser based quartz-enhanced photoacoustic spectroscopy sensor system for detection of carbon disulfide. Opt. Express 2016, 24, 6559-6571.

7. Ma, Y.F.; He, Y.; Yu, X.; Chen, C.; Sun, R.; Tittel, F.K. HCl ppb-level detection based on QEPAS sensor using a low resonance frequency quartz tuning fork. Sensor Actuat. B 2016, 233, 388-393. [CrossRef]

8. Liu, K.; Zhao, W.X.; Wang, L.; Tan, T.; Wang, G.S.; Zhang, W.J.; Gao, X.M.; Chen, W.D. Quartz-enhanced photoacoustic spectroscopy of HCN from 6433 to $6613 \mathrm{~cm}^{-1}$. Opt. Commun. 2015, 340, 126-130. [CrossRef]

9. Ma, Y.F.; Lewicki, R.; Razeghi, M.; Tittel, F.K. QEPAS based ppb-level detection of $\mathrm{CO}$ and $\mathrm{N}_{2} \mathrm{O}$ using a high power CW DFB-QCL. Opt. Express 2013, 21, 1008-1019. [CrossRef] [PubMed]

10. Wu, H.P.; Dong, L.; Zheng, H.D.; Liu, X.L.; Yin, X.K.; Ma, W.G.; Zhang, L.; Yin, W.B.; Jia, S.T.; Tittel, F.K. Enhanced near-infrared QEPAS sensor for sub-ppm level $\mathrm{H}_{2} \mathrm{~S}$ detection by means of a fiber amplified 1582 nm DFB laser. Sensor Actuat. B 2015, 221, 666-672. [CrossRef]

11. Ma, Y.F.; He, Y.; Zhang, L.G.; Yu, X.; Zhang, J.B.; Sun, R.; Tittel, F.K. Ultra-high sensitive acetylene detection using quartz-enhanced photoacoustic spectroscopy with a fiber amplified diode laser and a $30.72 \mathrm{kHz}$ quartz tuning fork. Appl. Phys. Lett. 2017, 110, 031107. [CrossRef]

12. Lassen, M.; Lamard, L.; Feng, Y.; Peremans, A.; Petersen, J.C. Off-axis quartz-enhanced photoacoustic spectroscopy using a pulsed nanosecond mid-infrared optical parametric oscillator. Opt. Lett. 2016, 41, 4118-4121. [CrossRef] [PubMed]

13. Zheng, H.D.; Dong, L.; Sampaolo, A.; Patimisco, P.; Ma, W.G.; Zhang, L.; Yin, W.B.; Xiao, L.T.; Vincenzo, S.; Jia, S.T. Overtone resonance enhanced single-tube on-beam quartz enhanced photoacoustic spectrophone. Appl. Phys. Lett. 2016, 109, 111103. [CrossRef]

14. Borri, S.; Patimisco, P.; Galli, I.; Mazzotti, D.; Giusfredi, G.; Akikusa, N.; Yamanishi, M.; Scamarcio, G.; Natale, P.; Spagnolo, V. Intracavity quartz-enhanced photoacoustic sensor. Appl. Phys. Lett. 2014, 104, 091114. [CrossRef]

15. Mordmüller, M.; Köhring, M.; Schade, W.; Willer, U. An electrically and optically cooperated QEPAS device for highly integrated gas sensors. Appl. Phys. B 2015, 119, 111-118. [CrossRef]

16. Cao, Y.C.; Jin, W.; Ho, L.H.; Liu, Z.B. Evanescent-wave photoacoustic spectroscopy with optical micro/nano fibers. Opt. Lett. 2012, 37, 214-216. [CrossRef] [PubMed]

17. Ma, Y.F.; Yu, X.; Yu, G.; Li, X.D.; Zhang, J.B.; Chen, D.Y.; Sun, R.; Tittel, F.K. Multi-quartz enhanced photoacoustic spectroscopy. Appl. Phys. Lett. 2015, 107, 021106. [CrossRef]

18. Patimisco, P.; Sampaolo, A.; Dong, L.; Tittel, F.K.; Spagnolo, V. Recent advances in quartz enhanced photoacoustic sensing. Appl. Phys. Rev. 2018, 5, 011106. [CrossRef] 
19. Patimisco, P.; Sampaolo, A.; Dong, L.; Giglio, M.; Scamarcio, G.; Tittel, F.K.; Spagnolo, V. Analysis of the electro-elastic properties of custom quartz tuning forks for optoacoustic gas sensing. Sensor Actuat. B 2016, 227, 539-546. [CrossRef]

20. Patimisco, P.; Sampaolo, A.; Zheng, H.; Dong, L.; Tittel, F.K.; Spagnolo, V. Quartz-enhanced photoacoustic spectrophones exploiting custom tuning forks: A review. Adv. Phys. X 2017, 2, 169. [CrossRef]

21. Borri, S.; Patimisco, P.; Sampaolo, A.; Beere, H.E.; Ritchie, D.A.; Vitiello, M.S.; Scamarcio, G.; Spagnolo, V. Terahertz quartz enhanced photoacoustic sensor. Appl. Phys. Lett. 2013, 103, 021105. [CrossRef]

22. Petra, N.; Zweck, J.; Kosterev, A.A.; Minkoff, S.E.; Thomazy, D. Theoretical analysis of a quartz-enhanced photoacoustic spectroscopy sensor. Appl. Phys. B 2009, 94, 673-680. [CrossRef]

23. Dong, L.; Kosterev, A.A.; Thomazy, D.; Tittel, F.K. QEPAS spectrophones: Design, optimization, and performance. Appl. Phys. B 2010, 100, 627-635. [CrossRef]

24. Ma, Y.F.; Yu, G.; Zhang, J.B.; Yu, X.; Sun, R.; Tittel, F.K. Quartz enhanced photoacoustic spectroscopy based trace gas sensors using different quartz tuning forks. Sensors 2015, 15, 7596-7604. [CrossRef] [PubMed]

(C) 2018 by the authors. Licensee MDPI, Basel, Switzerland. This article is an open access article distributed under the terms and conditions of the Creative Commons Attribution (CC BY) license (http:/ / creativecommons.org/licenses/by/4.0/). 